\title{
Gyrodactylus orecchiae sp. n. (Monogenea: Gyrodactylidae) from farmed populations of gilthead seabream (Sparus aurata) in the Adriatic Sea
}

\author{
Giuseppe Paladini ${ }^{1,2,3}$, Joanne Cable ${ }^{4}$, Maria L. Fioravanti ${ }^{1}$, Patricia J. Faria ${ }^{4}$, David Di Cave ${ }^{5}$ \\ and Andrew P. Shinn ${ }^{3}$
}

\author{
${ }^{1}$ Department of Veterinary Public Health and Animal Pathology, University of Bologna, Italy; \\ ${ }^{2}$ Istituto Zooprofilattico Sperimentale dell'Abruzzo e del Molise "G. Caporale”, Teramo, Italy; \\ ${ }^{3}$ Institute of Aquaculture, University of Stirling, FK9 4LA, Scotland, UK; \\ ${ }^{4}$ School of Biosciences, Cardiff University, Cardiff, CF10 3AX, UK; \\ ${ }^{5}$ Department of Public Health and Cellular Biology, University of Tor Vergata, Rome, Italy
}

\begin{abstract}
Gyrodactylus orecchiae sp. n. (Monogenea, Gyrodactylidae) is described from the skin, fins, eyes and gills of juvenile Sparus aurata L. (gilthead seabream) following two outbreaks of gyrodactylosis amongst stocks held in inshore floating cages on the Adriatic coast of Albania and Croatia. Fish were heavily infected (1000+ gyrodactylids/fish) with G. orecchiae which reportedly resulted in $\sim 2-10 \%$ mortality amongst the infected stock. Morphologically, the haptoral hooks of G. orecchiae most closely resemble those of Gyrodactylus arcuatus Bychowsky, 1933 in the approximate shape of the ventral bar with its pronounced ventral bar processes and marginal hook sickles which possess a square line to the inner edge of the sickle blade and large rounded heels. The marginal hooks are also morphologically similar to those of Gyrodactylus quadratidigitus Longshaw, Pursglove et Shinn, 2003 and Gyrodactylus colemanensis Mizelle et Kritsky, 1967, but G. orecchiae can be readily discriminated from all three species by the characteristic infolding of the hamuli roots and the shape of the marginal hook sickle. Molecular sequencing of the ITS1, 5.8S, ITS2 regions $(513+157+404 \mathrm{bp}$, respectively) of $G$. orecchiae and alignment with other gyrodactylids for which these same genomic regions have been determined, suggests that this is a new species. No similarities were found when the ITS1 region of G. orecchiae was compared with 84 species of Gyrodactylus available on GenBank.
\end{abstract}

Key words: Monogenea, Gyrodactylus orecchiae, gilthead seabream, Sparus aurata, Croatia, Albania

Monogeneans, notably infections with the microcotylid Sparicotyle chrysophrii (van Beneden et Hesse, 1863 ) and the diplectanid Furnestinia echeneis (Wagener, 1857), are commonly encountered in both cultured and wild populations of gilthead seabream Sparus aurata L. (Sparidae) within the Mediterranean (Euzet 1984, Radujkovic and Euzet 1989, Di Cave et al. 1998, Varriale and Baroncelli 1998, De Liberato et al. 2000). Of these, the report by De Liberato et al. (2000) and a chemotherapy study by Santamarina et al. (1991) also refer to the presence of an unidentified Gyrodactylus von Nordmann, 1832 on S. aurata. During 2005-2006, routine diagnostic sampling of inshore floating gilthead seabream cages at Orikum, Albania and Ugljan Island, Croatia revealed heavy infections with gyrodactylids on the skin and gills of juvenile stock. Infected fish were observed to be hypermelanotic, lethargic, anorexic and displayed a progressive loss of weight. Stock mortality was determined to be
$2-5 \%$ within the inland-based farm at Orikum, rising to $10 \%$ in the floating cages at the same location. Looking at the on-line database "GyroDb" (www.gyrodb.net, Harris et al. 2008), only one other gyrodactylid, Gyrodactylus alviga Dmitrieva et Gerasev, 2000, is known to parasitize the sparids Diplodus annularis (L.) and Sarpa salpa (L.) from the Black Sea (Dmitrieva and Gerasev 2000). Given the increasing importance of $S$. aurata in the Mediterranean as a species for aquaculture $(86,700$ tonnes in 2006; FAO/GLOBEFISH 2007), this study was undertaken to describe a new species of Gyrodactylus using molecular, light and scanning electron microscopy techniques.

\section{MATERIALS AND METHODS}

Collection of material and morphological determination. At each of the two farm sites (Fig. 1), approximately 20 juvenile S. aurata (weight ca. 5-10 g) were randomly sampled from several cages, killed by pithing and then fixed immediately in $70 \%$ 


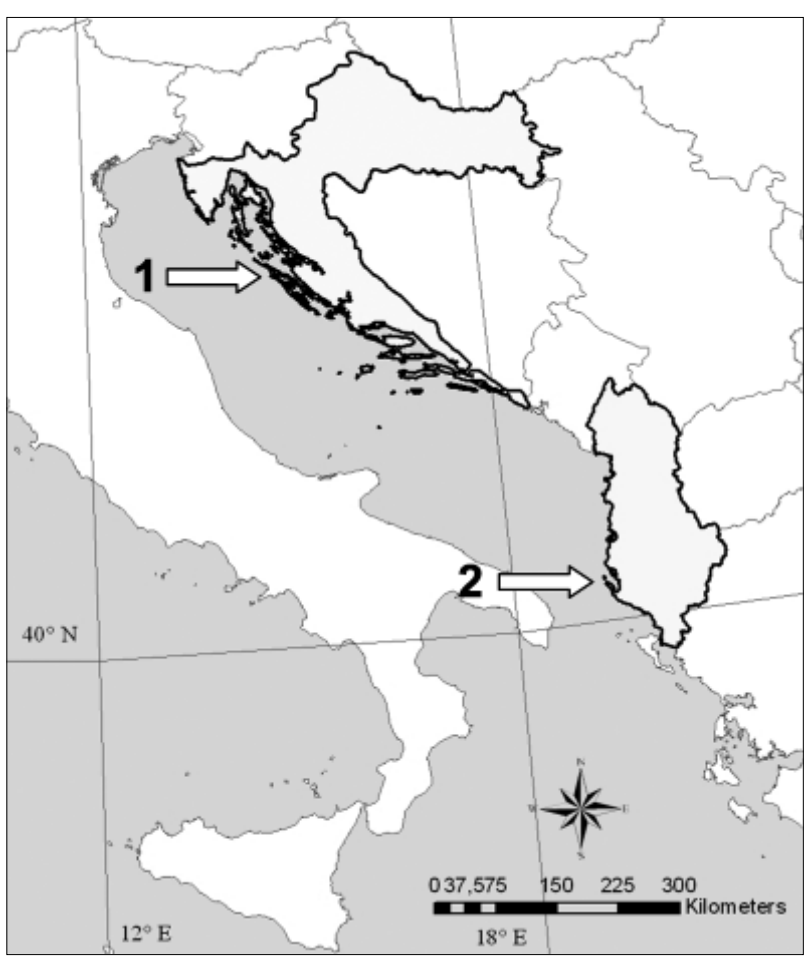

Fig. 1. Gyrodactylus orecchiae sp. n. sample sites within the Adri-

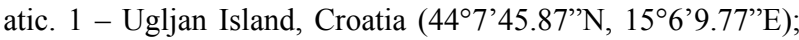
2 - Orikum, Albania (4018'50.92”N, 19²8’32.93”E).

ethanol. On return to the laboratory at the University of Bologna, the fish were screened using an Olympus SZ40 stereomicroscope at $\times 4$ magnification and specimens of Gyrodactylus were removed using mounted triangular surgical needles (size 16, Barber of Sheffield, UK). All fish (i.e. 2 sites; $n=40$ fish screened) were found to be infected with mean intensities in excess of 1,000 gyrodactylids per fish; no other metazoan parasites were detected. A further five fish from each site were processed for histology following standard procedures.

Parasite specimens were washed in distilled water and representatives prepared as whole mounts by clearing them in ammonium picrate glycerine following the procedure detailed by Malmberg (1970). A further 40 worms were removed, washed in distilled water and then digested on glass slides using a modification of the proteolytic method given in Harris and Cable (2000) and then mounted in ammonium picrate. The haptoral hooks of ten specimens were digested on $11 \mathrm{~mm}$ round glass coverslips, sputter-coated with gold and then examined using a JEOL JSM 5200 scanning electron microscope operating at an accelerating voltage of $25 \mathrm{kV}$. Five specimens were removed from their hosts, their haptors excised and prepared for proteolytic digestion and morphological study while the bodies were fixed in $95 \%$ ethanol for molecular characterisation.

For the morphological study, the haptoral hard parts were studied and drawn at magnifications of $\times 40$ and $\times 100$ oil immersion from images grabbed using a Zeiss AxioCam MRc digital camera interfacing with an Olympus $\mathrm{BH} 2$ compound microscope using a $\times 0.75$ lens and MRGrab 1.0.0.4 (Carl Zeiss Vision $\mathrm{GmbH}, 2001$ ) software. A total of 27 point-to-point morphometric measurements were made on haptoral hooks of each specimen from images grabbed using a JVC KY-F30B 3CCD video camera mounted on an Olympus $\mathrm{BH} 2$ microscope using a 2.5 interfacing lens at $\times 100$ oil immersion and KS300 (ver.3.0) (Carl Zeiss Vision GmbH, 1997) image analysis software. The measurements follow those given in Shinn et al. (2004) and are expressed in micrometres as the mean \pm standard deviation followed by the range in parentheses, unless otherwise stated.

Molecular characterisation. Sequencing of the ITS1, 5.8S and ITS2 regions of $G$. orecchiae was performed using primers P3b (TAGGTGAACCTGCAGAAGGATCA) and P4 (GTCCGGATCCTCCGCTTATTGAATGC) (Cable et al. 2005) which anneal to the $18 \mathrm{~S}$ and $28 \mathrm{~S}$, respectively. Amplifications were carried out in a Perkin Elmer thermocycler (9700) using an initial denaturation of $95^{\circ} \mathrm{C}$, followed by 35 cycles of $94^{\circ} \mathrm{C} 30 \mathrm{~s}$, $50{ }^{\circ} \mathrm{C} 1 \mathrm{~min}, 72{ }^{\circ} \mathrm{C} 2 \mathrm{~min}$ and a final extension of $72{ }^{\circ} \mathrm{C} 10 \mathrm{~min}$. PCR products were purified using Exonuclease $I$ and SAP (Shrimp Alkaline Phosphatase) (Biolabs) and both strands were sequenced using BigDye (version 3.1; Applied Biosystems) on an ABI3100 sequencer. Strands were manually aligned and corrected using the program BioEdit (Hall 1999).

The consensus sequence from three individuals were aligned with EMBLALIGN: Align_000605 (Matějusová et al. 2003) using CLUSTAL X (Jeanmougin et al. 1998) following the criteria detailed by Matějusová et al. (2003) and deleting the hypervariable sections of the ITS1 and ITS2 in order to optimize the alignment without ambiguities. The following sequences from GenBank were used for the alignment analysis: Gyrodactylus alburniensis Prost, 1972 (AY278032); G. alexgussevi Ziętara et Lumme, 2003 (AY061979); G. anguillae Ergens, 1960 (AB063294); G. arcuatus Bychowsky, 1933 (AF328865); G. branchicus Malmberg, 1964 (AF156669); G. bullatarudis Turnbull, 1956 (AY692024); G. cichlidarum Paperna, 1968 (DQ124228); G. elegans von Nordmann, 1832 (AJ407870); G. flesi Malmberg, 1957 (AY278039); G. lotae Gusev, 1953 (AY061978); G. macronychus Malmberg, 1957 (AY061980 and AY061981); G. cf. niger Huyse, Audenaert et Volckaert, 2003 (AY338452); G. pictae Cable, van Oosterhout, Barson et Harris, 2005 (AY692023); G. rarus Wegener, 1910 (AY338445); G. robustus Malmberg, 1957 (AY278040); G. rugiensis Gläser, 1974 (AF328870); G. rugiensoides Huyse et Volckaert, 2002 (AJ427414); G. salaris Malmberg, 1957 (AF328871); and G. turnbulli Harris, 1986 (AJ001846). MEGA version 4.0 (Tamura et al. 2007) was used to estimate $p$-distance between species.

\section{RESULTS}

\section{Gyrodactylus orecchiae sp. n. $\quad$ Figs. 2-4, Table 1}

Morphological description. Coverslip-flattened specimens 275.0-455.9 (356.3) long; 62.1-92.1 (81.5) wide at level of uterus. Anterior bulb of pharynx 25.1 (22.8-28.5) long $\times 41.3(36.7-46.9)$ wide bearing 8 processes 11.5 (8.9-15.2) long; posterior bulb 18.3 (12.8-22.6) long $\times$ 51.7 (44.8-67.2) wide. Intestinal crura, short, extend to the posterior end of uterus. Haptor, sub-ovate to spherical when attached, clearly delineated from body, 76.8 (67.6-96.1) long $\times 65.0(50.0-77.7)$ wide (Fig. 3e, f) Male copulatory organ ventro-lateral to posterior pharyngeal bulb or posterior to it, $13.8(11.0-15.4)$ long $\times 13.7$ 

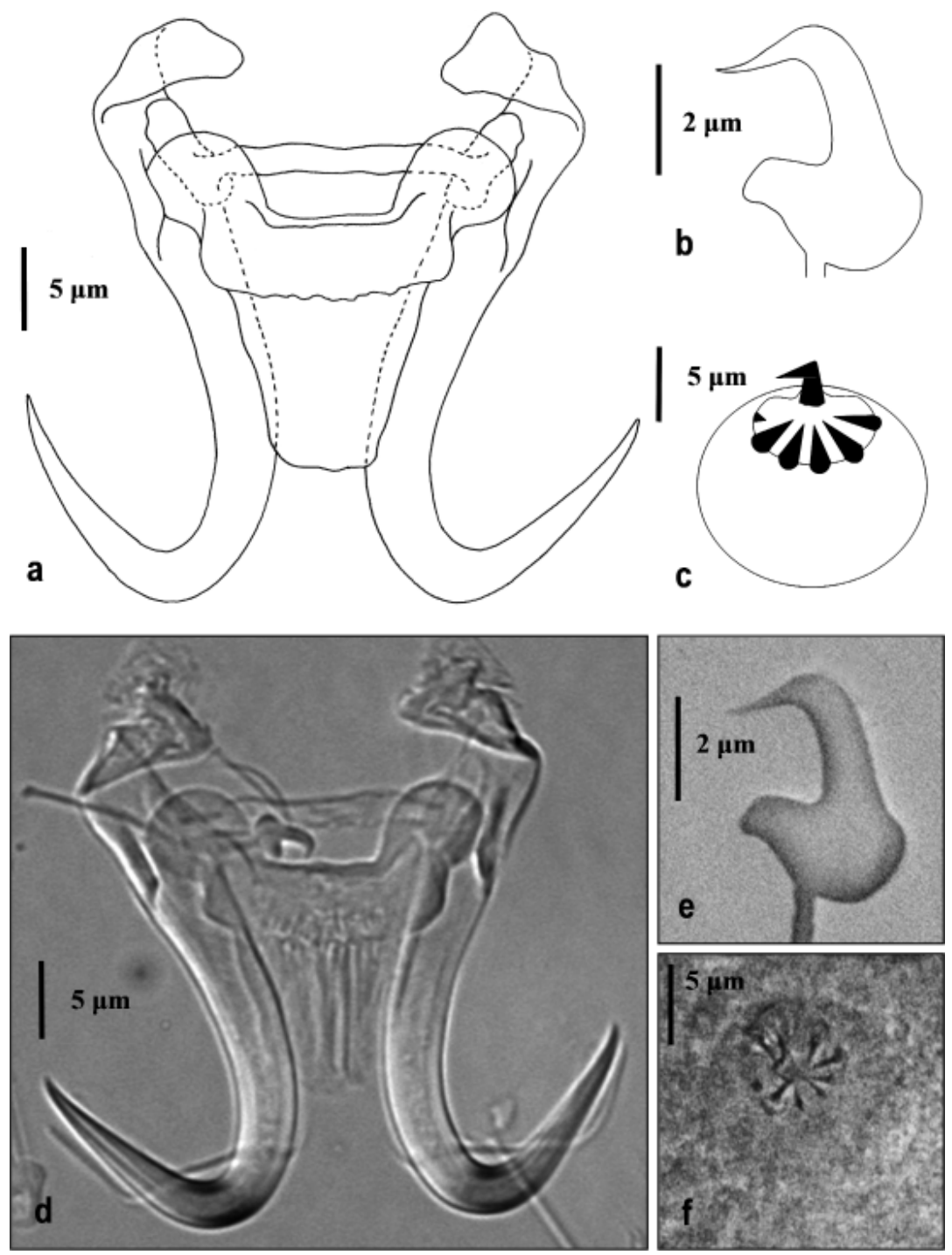

Fig. 2. Gyrodactylus orecchiae sp. n. a, d - the haptoral central hook complex of hamuli, dorsal and ventral bars; b, e - marginal hook sickle; $\mathbf{c}, \mathbf{f}$ - male copulatory organ showing one large apical spine and a single row of five equal-sized small spines.

(11.1-16.6) wide, spherical, armed with large apical hook and single arch of 5 (4-6) small even-sized spines (Fig. 2c, f). Hamuli total length 34.6 (32.6-38.1); shaft length $21.1(20.2-22.6)$; point $15.7(14.6-16.2)$ long with a $37.3^{\circ}$ $\left(33.3-40.6^{\circ}\right)$ aperture; inwardly directed roots 10.2 (7.714.2) long with central depression and thickened margins (Figs. 2a, d, 3a). Dorsal bar 16.4 (15.5-18.2) long; 2.1 (1.8-2.3) wide (Figs. 2a, d, 3a). Ventral bar 20.6 (18.622.0) long; 21.7 (19.0-24.0) wide; ventral bar processes prominent, rounded, 4.6 (4.0-5.6) long; ventral bar membrane lingulate, posteriorly rounded, $10.6(9.3-11.8)$ long (Figs. 2a, d, 3a). Marginal hook length 18.2 (17.5-18.7); shaft length 14.7 (14.2-15.9); sickle proper length 3.3 (3.0-4.0); sickle base tangential to plane of shaft with proximal width 3.2 (2.6-3.5); rhomboid toe 1.8 (1.2-2.0) long; heel rounded; sickle shaft parallel to long axis of entire hook; sickle point perpendicular to sickle shaft, ta- pers to fine point with distal width 2.2 (1.9-2.5); sickle aperture 3.4 (3.1-3.8); inner curve of sickle proper approximately rhomboid (Figs. 2b, e, 3b1-b5).

Type host: Sparus aurata L. (gilthead seabream), Sparidae. S i t e: Skin, fins, eyes and gill filaments.

Type locality: Orikum, Albania $\left(40^{\circ} 18^{\prime} 50.92\right.$ " N, $\left.19^{\circ} 28^{\prime} 32.93 " \mathrm{E}\right)$

Other reported localities: Ugljan Island, Croatia



Type material: Forty specimens were studied for light microscopy and ten digested specimens for SEM studies. Holotype (BMNH Reg. No. 2008.12.15.1) and paratype (BMNH Reg. No. 2008.12.15.2) are deposited in the parasitic worm collection at The Natural History Museum, London. Additionally, one paratype (M-475) is deposited in the gyrodactylid collection held at the Institute of Parasitology, Biology Centre of the Academy of Sciences of the Czech Republic, České Budějovice. 

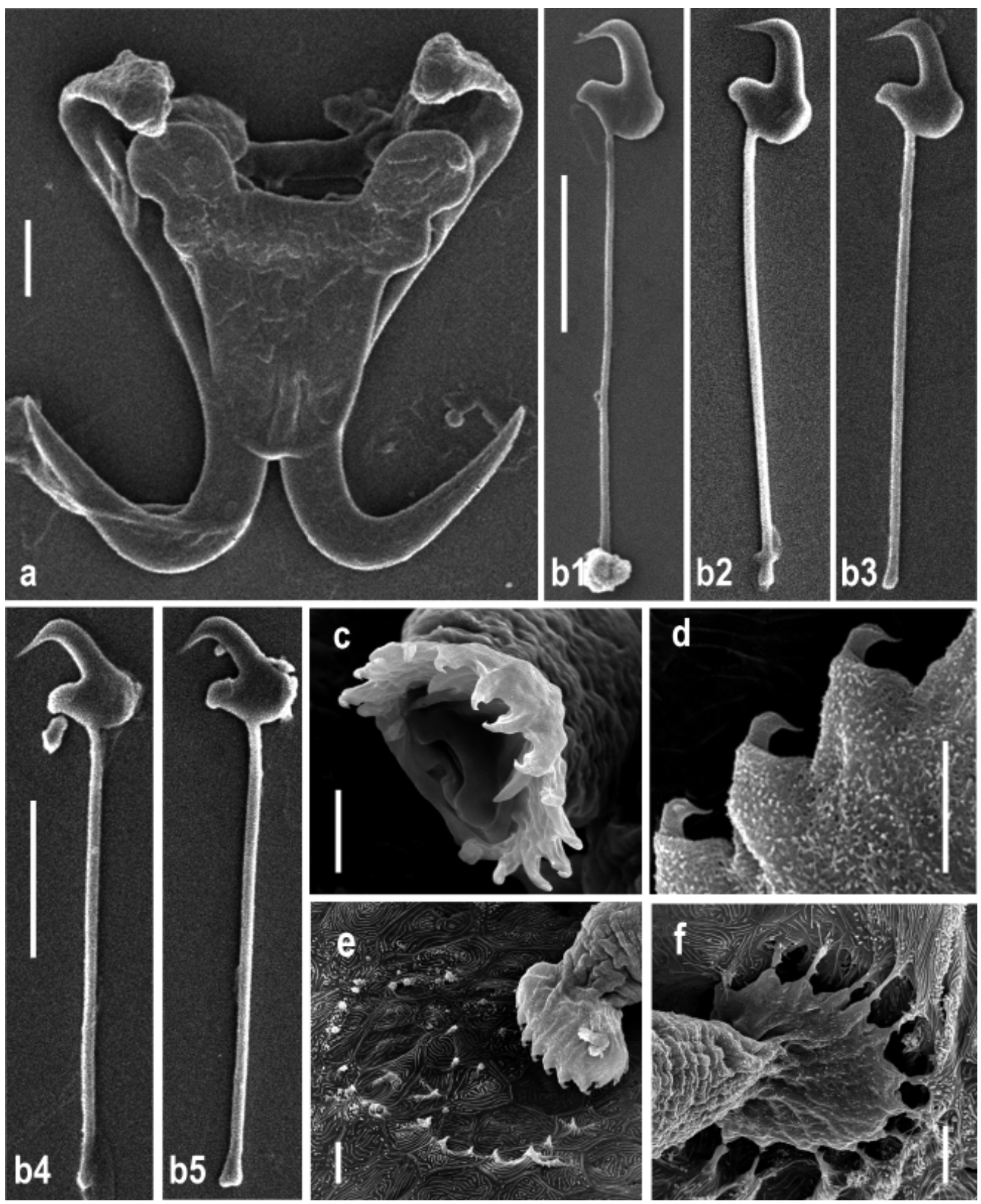

Fig. 3. Scanning electron micrographs of Gyrodactylus orecchiae sp. $n$. a - central hook complex showing the characteristic inwardly directed hamuli roots; b1-b5 - marginal hooks; c - ventral surface of the haptor showing the position of the ventral and dorsal bar which may project into the epithelium of its host, preventing the haptor from slipping backwards, promoting the efficiency of attachment; $\mathbf{d}$ - characteristic marginal hook sickle points projecting from the haptoral tegument; $\mathbf{e}$ - attachment wound; $\mathbf{f}$ - sub-ovate haptor. Scale bars: $\mathrm{a}, \mathrm{b} 1-\mathrm{b} 5, \mathrm{~d}=5 \mu \mathrm{m} ; \mathrm{c}, \mathrm{e}, \mathrm{f}=10 \mu \mathrm{m}$.

Molecular sequence data: The $1147 \mathrm{bp}$ amplified fragment (18S (1-16) + ITS1 (17-529) + 5.8S (530-686) + ITS2 (687-1090) + 28S (1091-1147)) is deposited in GenBank under Accession Number FJ013097.

E t y m o log y: Named in honour of Professor Paola Orecchia.

Histopathology. Acute dermatitis (hyperplasia and necrosis) was observed in the seabream with large numbers $(1000+)$ of Gyrodactylus attached to the epidermis; epidermal spongiosis and some hydropic degeneration was also evident. Infections by Gyrodactylus on the gills showed secondary infection by bacteria with cellular exfoliation and mild haemorrhaging.

Molecular characterisation. The amplified nucleotide sequence of the rDNA cluster was $1147 \mathrm{bp}$ and consisted of the 3' end of the 18S subunit (16 bp), the ITS1 (513 bp), the 5.8S gene (157 bp), the ITS2 (404 bp) and the 5 ' end of the $28 \mathrm{~S}$ subunit ( $57 \mathrm{bp}$ ). Submitting the ITS1 to a BLASTN (Altschul 1991) search revealed no related sequences while a search using the $5.8 \mathrm{~S}$ gave total ho- 
Table 1. Morphological measurements (mean \pm standard deviation followed by the range in parentheses; in micrometres) of Gyrodactylus orecchiae sp. n. from Sparus aurata collected from Orikum, Albania, which are respectively compared with those of Gyrodactylus arcuatus Bychowsky, 1933 from freshwater Gasterosteus aculeatus, Gyrodactylus arcuatus Bychowsky sensu Bychowsky et Poljansky, 1953 from Gasterosteus aculeatus from the Baltic Sea off Sweden, and Gyrodactylus quadratidigitus Longshaw, Pursglove et Shinn, 2003 from Thorogobius ephippiatus. Measurements taken from original descriptions in the literature are shown in a bold font, whilst those in regular font represent new measurements made in the current study. New measurements for G. quadratidigitus are provided from a syntype.

\begin{tabular}{|c|c|c|c|c|}
\hline Measurement & $\begin{array}{l}\text { G. orecchiae sp. } n . \\
(n=40)\end{array}$ & $\begin{array}{l}\text { G. arcuatus } \\
\text { Bychowsky, } 1933 \\
(n=24)^{1}\end{array}$ & $\begin{array}{l}\text { G. arcuatus Bychowsky } \\
\text { sensu Bychowsky et } \\
\text { Poljansky, } 1953^{2}\end{array}$ & $\begin{array}{l}\text { G. quadratidigitus } \\
\text { Longshaw, Pursglove } \\
\text { et Shinn, } 2003\end{array}$ \\
\hline Total body length & $356.3 \pm 51.4(275.0-455.9)$ & $399.8 \pm 36.3(340.4-464.0)^{4}$ & $336-460$ & $430.0 \pm 63.0(334.0-486.0)$ \\
\hline Total body width & $81.5 \pm 7.6(62.1-92.1)$ & $102.1 \pm 14.3(82.4-122.6)^{4}$ & $100-128$ & $122.0 \pm 19.0(104.0-149.0)$ \\
\hline Haptor length $\times$ width & $\begin{array}{l}76.8 \pm 12.1(67.6-96.1) \\
\times 65.0 \pm 12.0(50.0-77.7)^{3}\end{array}$ & $\begin{array}{l}52.5 \pm 9.7(45.4-69.5) \\
\times 70.3 \pm 8.8(63.6-85.1)^{3}\end{array}$ & - & $\begin{array}{l}48.9 \pm 3.7(45-54) \\
\times 81.4 \pm 8.0(70.5-88.0)\end{array}$ \\
\hline $\begin{array}{l}\text { Pharynx length } \times \text { width } \\
\text { (anterior; posterior bulb) }\end{array}$ & $\begin{array}{l}\text { Ant: } 25.1 \pm 2.6(22.8-28.5) \\
\times 41.3 \pm 4.3(36.7-46.9) \\
\text { Post: } 18.3 \pm 3.4(12.8-22.6) \\
\times 51.7 \pm 8.0(44.8-67.2)^{3}\end{array}$ & $\begin{array}{l}\text { Ant: } 23.8 \pm 5.1(16.1-27.8) \\
\times 32.2 \pm 2.8(28.2-35.1) \\
\text { Post: } 14.9 \pm 3.8(8.6-18.3) \\
\times 39.7 \pm 2.9(35.7-42.7)^{3}\end{array}$ & - & $\begin{array}{l}30.0 \pm 1.8(28.5-32.5) \\
\times 30.3 \pm 2.7(27.0-33.5)\end{array}$ \\
\hline $\begin{array}{l}\text { Male copulatory or- } \\
\text { gan length } \times \text { width } \\
\text { Hamulus }\end{array}$ & $\begin{array}{l}13.8 \pm 1.7(11.0-15.4) \times \\
13.7 \pm 2.0(11.1-16.6)^{3}\end{array}$ & $\begin{array}{l}13.9 \pm 1.2(12.1-14.9) \\
\times 13.9 \pm 1.7(11.9-16.4)^{3}\end{array}$ & - & $\begin{array}{l}8.2 \pm 0.5(7.0-8.5) \text { armed } \\
\text { with } 5-7 \text { small spines }\end{array}$ \\
\hline Ham aperture & $11.5 \pm 0.6(10.5-12.4)$ & $17.1 \pm 1.0(15.0-19.0)$ & - & 12.0 \\
\hline Ham prox. shaft width & $5.5 \pm 0.3(5.0-6.4)$ & $6.7 \pm 1.0(5.0-9.3)$ & - & 6.2 \\
\hline Ham point length & $15.7 \pm 0.4(14.6-16.2)$ & $18.9 \pm 1.0(17.0-20.6)$ & $15.2-18.5$ & $14.0 \pm 1.6(12.3-15.5)$ \\
\hline Ham distal shaft width & $3.5 \pm 0.2(3.2-3.8)$ & $3.7 \pm 0.4(2.9-4.4)$ & - & 2.2 \\
\hline Ham shaft length & $21.1 \pm 0.6(20.2-22.6)$ & $26.0 \pm 1.2(24.1-27.1)$ & $28.3-32.9$ & $21.0 \pm 3.8(17.7-24.6)$ \\
\hline Ham inner curve length & $2.3 \pm 0.4(1.5-2.9)$ & $2.8 \pm 0.7(1.5-3.6)$ & - & 1.2 \\
\hline Ham aperture angle $\left(^{\circ}\right)$ & $37.3 \pm 2.2(33.3-40.6)$ & $44.0 \pm 4.1(37.0-53.6)$ & - & 44.0 \\
\hline Ham point curve angle $\left({ }^{\circ}\right)$ & $14.0 \pm 2.9(9.8-20.7)$ & $12.2 \pm 2.1(7.6-15.1)$ & - & 20.0 \\
\hline Inner ham apert angle $\left(^{\circ}\right)$ & $44.2 \pm 3.3(38.4-49.0)$ & $50.9 \pm 4.7(43.1-61.7)$ & - & $53.9 \pm 0.8(53.2-54.6)$ \\
\hline Ham root length & $10.2 \pm 1.9(7.7-14.2)$ & $11.1 \pm 1.2(8.2-13.9)$ & 9.6-13.7 & $10.0 \pm 0.9(8.9-11.1)$ \\
\hline Ham total length & $34.6 \pm 1.9(32.6-38.1)$ & $40.4 \pm 2.0(35.8-43.5)$ & $35.9-43.1$ & $28.0 \pm 3.8(24.4-31.8)$ \\
\hline \multicolumn{5}{|l|}{ Dorsal bar } \\
\hline DB total length & $16.4 \pm 1.0(15.5-18.2)^{3}$ & $16.0 \pm 0.9(14.9-16.8)^{3}$ & 17.4 & $12.3 \pm 0.9(11.4-13.4)$ \\
\hline DB width & $2.1 \pm 0.2(1.8-2.3)^{3}$ & $2.0 \pm 0.2(1.7-2.2)^{3}$ & 0.9 & $0.8 \pm 0.1(0.8-0.9)$ \\
\hline \multicolumn{5}{|l|}{ Ventral bar } \\
\hline VB total width & $21.7 \pm 1.3(19.0-24.0)$ & $23.6 \pm 2.0(20.6-27.5)$ & $15.7-20.0$ & $18.0 \pm 1.5(16.2-19.5)^{*}$ \\
\hline VB total length & $20.6 \pm 0.9(18.6-22.0)$ & $24.9 \pm 2.1(19.7-28.0)$ & $24.4-27.0$ & $12.1 \pm 0.7(11.3-13.0)^{*}$ \\
\hline VB process to mid-length & $5.2 \pm 0.7(4.0-7.5)$ & $8.0 \pm 0.9(5.6-9.7)$ & - & 3.0 \\
\hline VB median length & $5.0 \pm 0.4(4.3-5.8)$ & $4.9 \pm 0.7(3.6-6.0)$ & $3.9-5.2$ & 2.1 \\
\hline VB process length & $4.6 \pm 0.4(4.0-5.6)$ & $7.1 \pm 0.9(5.7-9.2)$ & - & $3.0 \pm 0.0(3.0-3.0)$ \\
\hline VB membrane length & $10.6 \pm 0.7(9.3-11.8)$ & $12.5 \pm 1.7(8.1-15.3)$ & 11.3-11.8 & $8.2 \pm 0.6(7.7-8.8)$ \\
\hline \multicolumn{5}{|l|}{ Marginal hook } \\
\hline $\mathrm{MH}$ total length & $18.2 \pm 0.3(17.5-18.7)$ & $22.4 \pm 1.3(20.3-24.4)$ & 19.6-22.2 & $25.2 \pm 1.1(24.2-31.8)$ \\
\hline MH shaft length & $14.7 \pm 0.4(14.2-15.9)$ & $18.2 \pm 1.2(15.9-20.2)$ & $15.7-18.3$ & $21.0 \pm 0.9(19.9-22.4)$ \\
\hline MH sickle length & $3.3 \pm 0.2(3.0-4.0)$ & $5.1 \pm 0.3(4.6-5.9)$ & 4.4 & $4.9 \pm 0.4(4.4-5.7)$ \\
\hline MH sick prox width & $3.2 \pm 0.2(2.6-3.5)$ & $3.9 \pm 0.3(3.4-4.3)$ & $3.5-3.9$ & $3.0 \pm 0.3(2.8-3.7)$ \\
\hline MH toe length & $1.8 \pm 0.2(1.2-2.0)$ & $1.4 \pm 0.1(1.1-1.7)$ & - & 1.1 \\
\hline MH sick dist width & $2.2 \pm 0.2(1.9-2.5)$ & $2.6 \pm 0.2(2.1-2.9)$ & 2.2 & $3.9 \pm 0.4(3.1-4.5)$ \\
\hline MH aperture & $3.4 \pm 0.2(3.1-3.8)$ & $3.9 \pm 0.3(3.4-4.3)$ & - & 3.8 \\
\hline MH instep / arch height & $0.4 \pm 0.1(0.3-0.5)$ & $0.6 \pm 0.1(0.4-0.8)$ & - & 0.2 \\
\hline
\end{tabular}

${ }^{1}$ Specimens taken from a freshwater population of Gasterosteus aculeatus L. from Loch Airthrey, Stirlingshire, Scotland (56 8'47.6” N, $\left.3^{\circ} 59^{\prime} 33.5^{\prime \prime} \mathrm{W}\right)$; ${ }^{2}$ Data taken from Malmberg (1970) represent specimens in marine environments; ${ }^{3}$ Based on the measurement of 5 specimens; ${ }^{4}$ Based on the measurement of 10 specimens; *The terms ventral bar length and width in this study are used in relation to longitudinal axis of the worm's body. The measurements in Longshaw et al. (2003), however, follow those of Malmberg (1970) and have been switched for direct comparison in this study. 

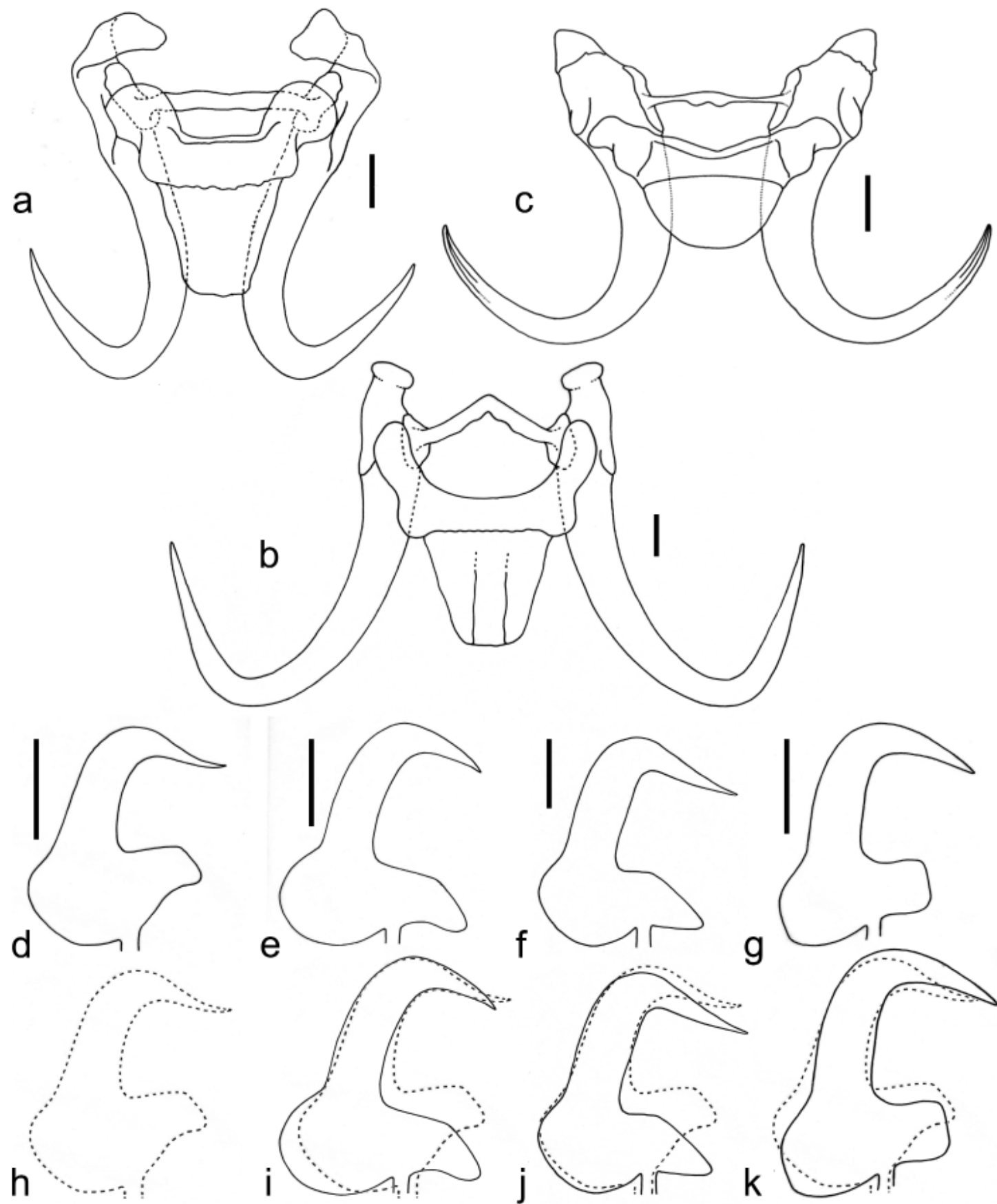

Fig. 4. A comparison of the haptoral hooks of Gyrodactylus orecchiae sp. n. with morphologically similar species. a-c-comparison of the central haptoral complex; a - G. orecchiae; b-G. arcuatus Bychowsky, 1933; c-G. quadratidigitus Longshaw, Pursglove et Shinn, 2003 (redrawn from original); $\mathbf{d}-\mathbf{g}$ - marginal hooks of four morphologically similar species; d - G. orecchiae; $\mathbf{e}-$ G. arcuatus; $\mathbf{f}-$ G. colemanensis Mizelle et Kritsky, 1967; $\mathbf{g}-$ G. quadratidigitus; $\mathbf{h}-\mathbf{k}$ - overlays of the marginal hook sickle for G. orecchiae with morphologically similar species (marginal hook sickles size invariant); $\mathbf{h}-G$. orecchiae as a broken line; $\mathbf{i}-$ overlay of $G$. orecchiae with G. arcuatus; $\mathbf{j}$ - overlay of G. orecchiae with G. colemanensis; $\mathbf{k}$ - overlay of G. orecchiae with G. quadratidigitus. Scale bars: $\mathrm{a}-\mathrm{c}=5 \mu \mathrm{m} ; \mathrm{d}-\mathrm{g}=2 \mu \mathrm{m}$.

mology ( $p$-distance $=0$ ) with Gyrodactylus alexgussevi, G. branchicus, G. flesi, G. lotae, G. rarus, G. robustus and G. rugiensoides. When the ITS2 was blasted separately, then the closest gyrodactylid with a homology of $78 \%$ (coverage of 97\%) was the Gyrodactylus species parasit- izing Gobius niger L. (see Huyse et al. 2003). Furthermore, homology of $86 \%$ on ITS2 (coverage of only $47 \%$ ) was also obtained with G. alexgussevi, G. branchicus, $G$. lotae and $G$. rarus ( $p$-distance $=0.101)$. 


\section{DISCUSSION}

Gyrodactylus orecchiae is the first species of this genus to be formally described from Sparus aurata although one other species, G. alviga, is recorded from two other sparid hosts, Diplodus annularis and Sarpa salpa (Dmitrieva and Gerasev 2000). The morphology of the attachment hooks of these two gyrodactylids, however, differs markedly. Although large ventral bar processes are a characteristic feature of many gyrodactylid species, notably among the Nearctic gyrodactylid fauna, viz. the freshwater species G. colemanensis Mizelle et Kritsky, 1967 from Salvelinus fontinalis (Mitchill), and the brackish/marine species viz. G. groenlandicus Levinsen, 1881 from Myoxocephalus scorpius (L.), G. nainum Hanek et Threlfall, 1970 from Triglopsis (Myoxocephalus) quadricornis (L.), G. pleuronecti Cone, 1981 from Pseudopleuronectes americanus (Walbaum) and G. stephanus Mueller, 1937 from Fundulus heteroclitus (L.), G. orecchiae can be discriminated from these other species based on the morphology of its marginal hook sickle. For example, when the marginal hook sickle of $G$. orecchiae is aligned to a morphologically similar species, such as G. colemanensis, although the shaft and point regions are proportionally alike and describe the same rhomboid inner curve to the sickle (Fig. $4 \mathrm{j}$ ), other marginal hook features allow their differentiation from each other. For example, the toe of G. colemanensis is triangular whilst that of G. orecchiae is square to rhomboid and is upwardly oriented in the direction of the sickle point. The sickle base of $G$. orecchiae is proportionally deep with a large rounded heel (Fig. $4 \mathrm{~d}, \mathrm{f}, \mathrm{j}$ ). The size of the marginal hooks of these two gyrodactylids also differ markedly: (31.1 (col) vs. 18.2 (orec) total length; 25.8 (col) vs. 14.7 (orec) shaft length; 6.0 (col) vs. 3.3 (orec) sickle length; 4.2 (col) vs. 3.2 (orec) sickle proximal width; 4.1 (col) vs. 2.2 (orec) sickle distal width, 1.5 (col) vs. 1.8 (orec) toe length; 4.6 (col) vs. 3.4 (orec) aperture) (data for G. colemanensis taken from Shinn 1993).

Two other morphologically similar species are G. arcuatus Bychowsky, 1933 (Fig. 4b, e) and G. quadratidigitus Longshaw, Pursglove et Shinn, 2003 (Fig. 4c, g). The former is known from both freshwater and marine populations of three-spined sticklebacks (Gasterosteus aculeatus L.) and as seen in G. orecchiae, it also possesses large ventral bar processes, hamuli roots that are commonly observed to turn inwards over the ventral bar processes, and marginal hooks with a square line to the inner edge of the sickle blade and large rounded heels. Gyrodactylus arcuatus, however, can be readily discriminated from G. orecchiae based on the shape of the sickle proper toe, which is long and triangular in the former (Fig. 4d, e, i).
Gyrodactylus quadratidigitus from Thorogobius ephippiatus (Lowe), prior to the current study, appeared to be unique in that it possesses marginal hooks with a square toe (Fig. 4g), a male copulatory organ (sic. cirrus) positioned in line with or anterior to the posterior pharyngeal bulb, and unusually short intestinal crura which do not extend beyond the level of the testis. The position of the male copulatory organ in mature specimens of $G$. orecchiae appears to be variable. It has been observed in positions ranging from medial or posterior to the posterior pharyngeal bulb to lateral, the centre of the male copulatory organ level with the posterior edge of the pharyngeal bulb. The intestinal crura of $G$. orecchiae also appear to be very short in that they do not extend beyond the most posterior limit of the uterus. It is the blunt-ended toe of the marginal hook sickle, however, of both G. orecchiae and G. quadratidigitus that are characteristic but the morphology of each is not so subtle as to prevent their discrimination from one another (Fig. 4d, g, k).

The angles at which the ventral bar processes and the hamuli roots project under the haptoral tegument and their alignment to one another create a series of ridges that may serve to increase the efficiency of attachment in this species (Fig. 3c). The apparently robust processes of the ventral bar, it is hypothesized, would press into the epidermal tissues of its host at an opposing angle to the principal force of action by the marginal hooks contributing to the worm's attachment and minimising the risks of its dislodgement.

Of the 409 species of Gyrodactylus described so far, only around $20 \%$ have been sequenced at the ITS. In the absence of molecular data for G. colemanensis and G. quadratidigitus, both of which are nominally "similar" to G. orecchiae, a thorough analysis of the taxonomic affinities of these species must await a more thorough molecular coverage of the group.

Acknowledgements. The authors would like to thank Dr. Michele Moscato and Dr. Paola Beraldo for providing infected material for study and Prof. Francesco Quaglio from the University of Padova for his help in interpreting the histology. We also thank Prof. Massimo Trentini from the University of Bologna for technical assistance with the acquisition of scanning electron photomicrographs and Dr. Cosimo Paladini and Dr. Sandro Pelini for their help in producing the map of the study area. This work was funded through a scholarship awarded to GP from the Degree Course in Aquaculture and Ichthyopathology, Cesenatico (FC), Italy, and a travel award from Dr. Nicola Ferri from the Istituto Zooprofilattico Sperimentale dell'Abruzzo e del Molise "G. Caporale", Teramo, Italy. PJF was supported by a European Community Framework Programme 6 Marie Curie Host Fellowship for Transfer of Knowledge (MTKD-CT-2005-030018). 


\section{REFERENCES}

Altschul S.F. 1991: Amino-acid substitution matrices from an information theoretic perspective. J. Mol. Biol. 219: 555-565.

Cable J., van Oosterhout C., Barson N., Harris P.D. 2005: Gyrodactylus pictae $\mathrm{n}$. $\mathrm{sp}$. from the Trinidadian swamp guppy Poecilia picta Regan, with a discussion on species of Gyrodactylus von Nordmann, 1832 and their poeciliid hosts. Syst. Parasitol. 60: $159-164$.

De Liberato C., Di Cave D., Berrilli F., Orecchia P. 2000: Fish parasites and related problems in Italian mariculture facilities. Parassitologia 42 (Suppl. 1): 166.

Di Cave D., De Liberato C., Berrilli F., Orecchia P. 1998: Parasitic infections of sharpsnout sea bream, Diplodus puntazzo and gilthead sea bream, Sparus aurata in cage culture. Parassitologia 40 (Suppl. 1): 45.

Dmitrieva E.V., Gerasev P.I. 2000: Two new species of Gyrodactylus (Gyrodactylidae, Monogenea) from Black Sea fishes. Vestn. Zool. 34: 98.

Euzet L. 1984: Diplectanidae (Monogenea) parasites de poissons des Iles Kerkenneh (Tunisie). Arch. Inst. Pasteur Tunis 61: 463474.

FAO/GLOBEFISH 2007: FAO/GLOBEFISH Seafood highlights 2007: A yearly up-date based on the GLOBEFISH databank. http://www.infofish.org.

GyroDв 2007: A home for gyrodactylids on the web. http://www. gyrodb.net.

HALL T.A. 1999: BioEdit: a user-friendly biological sequence alignment editor and analysis program for Windows 95/98/NT. Nucl. Acids Symp. Ser. 41: 95-98.

Harris P.D., Cable J. 2000: Gyrodactylus poeciliae n. sp. and G. milleri n. sp. (Monogenea: Gyrodactylidae) from Poecilia caucana (Steindachner) in Venezuela. Syst. Parasitol. 47: 79-85.

Harris P.D., Shinn A.P., Cable J., Bakke T.A., Bron J.E. 2008: GyroDb: gyrodactylid monogeneans on the web. Trends Parasitol. 24: 109-111.

Huyse T., Audenaert V., Volckaert F.A.M. 2003: Speciation and host-parasite relationships in the parasite genus Gyrodactylus (Monogenea, Platyhelminthes) infecting gobies of the genus Pomatoschistus (Gobiidae, Teleostei). Int. J. Parasitol. 33: 1679-1689.

Received 23 September 2008
Jeanmougin F., Thompson J.D., Gouy M., Higgins D.G., Gibson T.J. 1998: Multiple sequence alignment with Clustal X. Trends Biochem. Sci. 23: 403-405.

Longshaw M., Pursglove M., Shinn A.P. 2003: Gyrodactylus quadratidigitus n. sp. (Monogenea: Gyrodactylidae), a parasite of the leopard-spotted goby Thorogobius ephippiatus (Lowe) from the south-western coast of the UK. Syst. Parasitol. 55: 151-157.

Malmberg G. 1970: The excretory systems and the marginal hooks as a basis for the systematics of Gyrodactylus (Trematoda, Monogenea). Ark. Zool. 23: 1-235.

Matějusová I., Gelnar M., Verneau O., Cunningham C.O., LitTLEwood D.T.J. 2003: Molecular phylogenetic analysis of the genus Gyrodactylus (Platyhelminthes: Monogenea) inferred from rDNA ITS region: subgenera versus species groups. Parasitology 127: 603-611.

Radujkovic B.M., Euzet L. 1989: Parasites des poissons marins du Monténégro: Monogènes. Acta Adriat. 30: 51-135.

Santamarina M.T., Tojo J., Ubeira F.M., Quinteiro P., SanmarTIN M.L. 1991: Anthelminthic treatment against Gyrodactylus sp. infecting rainbow trout Oncorhynchus mykiss. Dis. Aquat. Org. 10: 39-43.

SHINN A.P. 1993: The application of new biosystematic techniques in the discrimination of the genus Gyrodactylus (Monogenea) on salmonoid fish. Ph.D. Thesis, University of Stirling, Scotland, UK, $341 \mathrm{pp}$.

Shinn A.P., Hansen H., Olstad K., Bachmann L., Bakke T.A. 2004: The use of morphometric characters to discriminate species of laboratory-reared and wild populations of Gyrodactylus salaris and G. thymalli (Monogenea). Folia Parasitol. 51: 239252.

Tamura K., Dudley J., Nei M., Kumar S. 2007: MEGA4: Molecular Evolutionary Genetics Analysis (MEGA) software version 4.0. Mol. Biol. Evol. 24: 1596-1599.

Varriale A.M., Baroncelli O.L. 1998: Gill parasites of sea bream Sparus aurata L. in the Orbetello lagoon. Parassitologia 40 (Suppl. 1): 179

Accepted 30 January 2009 